\title{
Perancangan dan pengembangan connector wheelchair sebagai alat bantu tuna daksa
}

\author{
Happy Ernesto Putra, ${ }^{1 *}$ Sunday Noya ${ }^{1}$ \\ ${ }^{1}$ Program Studi Teknik Industri, Universitas Ma Chung Malang, Indonesia
}

\begin{abstract}
In recent years the world community has begun to pay attention to the rights of disabled people not least the Government and the people of Indonesia. Much effort has been made from law enforcement to the provision of assistance to disabled people. The object of this research is disabled people in Malang. There is still a lack of facilities for disabled in terms of accessibility and uniqueness in Indonesia that are able to sell motorcycles with a large number, as well as with the development of smartphone technology that gave rise to the phenomenon of GoJek provides the idea to make transportation equipment safe, comfortable and cheap for disabled people tuna daksa. The tool is a wheelchair that can be attached to a motorcycle (connector wheelchair). The design and development of wheelchair connector is done using QFD phase 1 and Ergonomic method. The benefit of QFD 1 is to get wheelchair connector specifications. The output of this research is 3D design.
\end{abstract}

Key words: disabled people, QFD, ergonomic, product design

\begin{abstract}
Abstrak
Beberapa tahun belakangan ini masyarakat dunia mulai memperhatikan hak-hak penyandang disabilitas, tidak terkecuali pemerintah dan masyarakat Indonesia. Banyak upaya yang telah dilakukan mulai dari pembuatan undang-undang hingga pemberian bantuan kepada penyandang disabilitas. Obyek penelitian adalah penyandang tuna daksa di Malang. Masih kurangnya fasilitas bagi tuna daksa dalam hal aksesibilitas dan keunikan di Indonesia yang mampu menjual sepeda motor dengan jumlah yang banyak, serta dengan perkembangan teknologi smartphone yang memunculkan fenomena ojek online tersebut memberikan ide untuk membuat alat bantu transportasi yang aman, nyaman, dan murah bagi penyandang tuna daksa. Alat bantu tersebut ialah kursi roda yang dapat dipasangkan ke sepeda motor (connector wheelchair). Perancangan dan pengembangan connector wheelchair dilakukan menggunakan metode QFD tahap 1 dan Ergonomi. Manfaat dari QFD 1 adalah untuk mendapatkan spesifikasi connector wheelchair. Luaran dari penelitian ini adalah 3D desain.
\end{abstract}

Kata kunci: tuna daksa, QFD, ergonomi, desain produk

\section{Pendahuluan}

Beberapa tahun belakangan ini masyarakat dunia mulai memperhatikan hak-hak penyandang disabilitas, tidak terkecuali Pemerintah dan masyarakat Indonesia. Banyak upaya yang telah dilakukan mulai dari pembuatan undang-undang hingga pemberian bantuan kepada penyandang disabilitas. Namun ada beberapa permasalahan penyandang disabilitas yang belum sepenuhnya terselesaikan. Undang-undang Nomor 8 Tahun 2016 menyatakan bahwa sebagian besar penyandang disabilitas di Indonesia hidup dalam kondisi rentan, terbelakang, dan miskin (Pemerintah Republik Indonesia, 2016). Hal tersebut disebabkan karena masih adanya pembatasan, hambatan, kesulitan, dan pengurangan atau penghilangan hak penyandang disabilitas. Salah satu pelaksanaan dan pemenuhan hak penyandang disabilitas adalah pemenuhan hak aksesibilitas.

Badan Pusat Statistik menyebutkan bahwa Indonesia memiliki jumlah penduduk lebih dari 230 juta orang yang $62 \%$ di antaranya berdomisili di Pulau Jawa (Anonim, 2012). Padahal kenyataannya luas Pulau Jawa hanya 7,2 \% dari total luas wilayah Indonesia, sehingga masalah transportasi umum di

\footnotetext{
* Koresponden penulis e-mail : ernesthappy7@gmail.com
} 
Indonesia menjadi bertambah rumit. Kondisi ini menyebabkan terbatasnya ruang, biaya, dan keamanan yang dapat disediakan bagi penyandang disabilitas. Hampir semua fasilitas transportasi di Indonesia tidak teratur dan penuh sesak manusia, sehingga tidak ada kemungkinan menyediakan aksesibilitas yang memadai bagi penyandang disabilitas.

Infrastruktur di Indonesia yang ramah bagi seseorang yang memiliki kelainan fisik atau mental (difabel) masih terbilang minim. Umumnya, fasilitas yang dapat digunakan oleh tuna daksa untuk bepergian jauh adalah mobil, bis, dan lain-lain. Akan tetapi tidak semua penyandang disabilitas mempunyai mobil dan bisa menggunakan kendaraan umum. Hingga saat ini, belum ada fasilitas sederhana yang mampu mengantarkan mereka ke tempat-tempat yang berada di sekitar tempat tinggal mereka dengan dengan aman, nyaman, dan murah. Disisi lain, Indonesia mempunyai keunikan tersendiri yaitu jumlah kepemilikan kendaraan sepeda motor yang sangat tinggi. Menurut detikOTO data penjualan sepeda motor di Indonesia periode Januari-Juni 2017 sebanyak 2.700.546 unit (Rahadiansyah, 2017).

Dewasa kini perkembangan teknologi smartphone berkembang begitu pesat. Banyak aplikasi-aplikasi online yang membantu memudahkan penggunanya dalam melakukan aktivitas. Hal tersebut membuat sebagian orang menciptakan aplikasi yang bergerak di bidang jasa antara lain, GoJek, Grab, dan lain-lain. Kini fenomena jasa ojek online sudah sangat populer di beberapa kota di Indonesia. Selain murah, sepeda motor juga bisa menjangkau daerah yang tidak bisa dilalui mobil dan kendaraan umum lainnya. Masih kurangnya fasilitas bagi tuna daksa dalam hal aksesibilitas dan keunikan di Indonesia yang mampu menjual sepeda motor dengan jumlah yang banyak, serta dengan perkembangan teknologi smartphone yang memunculkan fenomena ojek online tersebut memberikan ide untuk membuat alat bantu transportasi yang aman, nyaman, dan murah bagi penyandang tuna daksa. Alat bantu tersebut ialah kursi roda yang dapat dipasangkan ke sepeda motor (connector wheelchair). Hanya dengan menggunakan smartphone dan memesan jasa ojek online penyandang tuna daksa mampu bepergian dengan jarak yang cukup jauh dari jarak mereka bepergian menggunakan kursi roda mereka. Alat ini diharapkan dapat menyelesaikan permasalahan aksesibilitas dan membantu mobilisasi para penyandang disabilitas khususnya tuna daksa di Indonesia agar lebih mandiri.

\section{Bahan dan Metode}

Metode yang digunakan adalah QFD dan ergonomi. Quality Function Deployment (QFD) adalah metode perencanaan dan pengembangan secara terstruktur yang memungkinkan tim pengembang mendefinisikan secara jelas kebutuhan dan harapan pelanggan, dan mengevaluasi kemampuan produk atau jasa secara sistematik guna memenuhi kebutuhan dan harapan tersebut (Ariani, 2002). Ergonomi adalah suatu keilmuan multidisiplin yang mempelajari pengetahuan dari ilmu-ilmu kehayatan (kedokteran, biologi), ilmu kejiwaan (psychology), dan kemasyarakatan (sosiologi). Selain itu juga metode yang digunakan adalah metode perancangan dan pengembangan produk. Proyek perancangan dan pengembangan produk dapat dikelompokkan menjadi 4 tipe yaitu, platform produk baru, turunan dari platform produk yang telah ada, peningkatan perbaikan untuk produk yang telah ada, dan pada dasarnya produk baru (Ulrich \& Eppinger, 2012).

Perkembangannya saat ini QFD digunakan dalam berbagai jenis penelitian. Penelitian tersebut antara lain QFD digunakan untuk merencanakan proses manisan wortel (Noya, Ekawati, \& Utami, 2017), QFD digunakan untuk merencanakan proses kualitas sirup wortel (Ekawati, Noya, \& Widjaja, 2017), QFD juga dapat digabungkan dengan analisis intergrasi Fuzzy-Servqual untuk meningkatkan kualitas pelayanan pada KSP Kusuma Artha Lestari (Wijayanti \& Noya, 2017), QFD digabungkan dengan Fuzzy AHP untuk menentukan bobot penting untuk kebutuhan pelanggan (Kwong \& Bai, 2003). Selain itu QFD dapat digabungkan dengan teori pendekatan pemecahan masalah inovasi untuk desain produk ergonomis (Zhang, Yang, \& Liu, 2014).

\section{Hasil dan Pembahasan}

Prosess penentuan spesifikasi target produk dengan menggunakan metode QFD didapatkan 7 atribut kebutuhan konsumen. Atribut-atribut tersebut adalah material rangka kuat dan tahan lama, kursi memiliki sabuk pengaman, kursi roda memiliki shock absorber, connector harus kuat, kursi aman dan nyaman, roda depan dapat dilipat, serta ketinggian kursi dapat diatur. Atribut kebutuhan konsumen yang mendapatkan proporsi tinggi adalah atribut kebutuhan konsumen kursi memiliki sabuk pengaman, kursi roda memiliki shock absorber, connector harus kuat, roda depan dapat dilipat, serta ketinggian kursi dapat diautur. Nilai proporsi yang tinggi menunjukan atribut-atribut tersebut mendapatkan prioritas yang 
paling besar. Dikarenakan atribut-atribut tersebut adalah fitur-fitur baru yang akan diterapkan pada connector wheelchair, maka membutuhkan inovasiinovasi baru untuk dikembangkan.

Selain itu, didapatkan pula 12 atribut persyaratan teknis. Atribut-atribut tersebut adalah pemilihan material rangka kursi roda, ada mekanisme penggerak linear naik turun, desain sandaran dan tempat duduk ergonomis, struktur connector tahan terhadap tegangan, dimensi connector, dimensi roda, teknik penyambungan yang tepat dan benar, ada mekanisme untuk melipat roda depan, pengecatan teknik pemasangan sabuk pengaman, penempatan shock absorber yang tepat dan desain kursi roda yang aerodimanis.

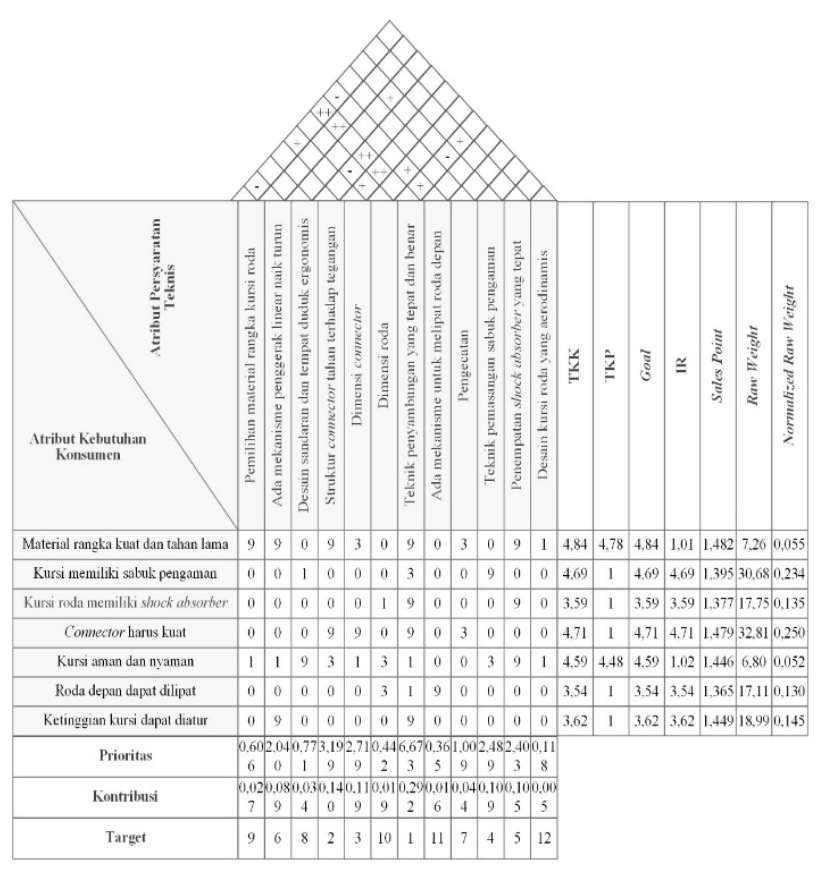

Gambar 1. Matriks HOQ

Berdasarkan atribut kebutuhan konsumen didapatkan enam sub-masalah. Sub-masalah tersebut antara lain mengenai material rangka, keamanan connector wheelchair, kenyamanan connector wheelchair, mekanisme yang digunakan pada connector, mekanisme penggerak linear untuk menaikan dan menurunkan tempat duduk pada connector wheelchair, serta mekanisme untuk melipat roda depan.

Atribut kebutuhan konsumen kursi/tempat duduk aman dan nyaman dihilangkan karena untuk atribut keamaan connector wheelchair telah diwakilkan dengan atribut kursi roda memiliki sabuk pengaman, sedangkan untuk atribut kenyamanan connector wheelchair telah diwakilkan dengan atribut kursi roda memiliki shock absorber/breaker. Berikut merupakan penjelasan mengenai sub-masalah tersebut: (1) Material rangka, yaitu pemilihan material yang digunakan untuk membuat rangka connector wheelchair. (2) Keamanan, yaitu jenis sabuk pengaman yang digunakan pada connector wheelchair. (3) Kenyamanan, yaitu jenis peredam kejut yang digunakan pada connector wheelchair. (4) Mekanisme connector, yaitu cara menghubungkan connector wheelchair dengan sepeda motor. (5) Mekanisme penggerak linear, yaitu cara mengatur ketinggian kursi agar dapat dinaikan dan diturunkan. (6) Mekanisme melipat roda depan, yaitu cara melipat roda depan agar tidak menghalangi connector wheelchair ketika digunakan menggunakan sepeda motor.

Berdasarkan hasil penentuan sub-masalah di atas, selanjutnya akan dicari solusi yang tepat bagi submasalah yang ada. Tabel 1 memperlihatkan beberapa solusi yang bisa diterapkan untuk mengatasi submasalah tersebut.

Tabel 1. Sub-masalah dan solusi

\begin{tabular}{ll}
\hline \multicolumn{1}{c}{ Sub-Masalah } & \multicolumn{1}{c}{ Solusi } \\
\hline Material rangka & - Frame steel \\
& - Frame aluminium \\
Keamanan & - Sabuk chromoly \\
& - Sabuk pengaman dua titik \\
Kenyamanan & - Mono shock absorber/breaker \\
Mekanisme connector & - Mur baut \\
& - Pas \\
Mekanisme penggerak linear & - Hidrolis \\
& - Seat clamp \\
Mekanisme melipat roda depan & - Engsel gir \\
& - Magnet \\
\hline
\end{tabular}

Berdasarkan beberapa alternatif solusi dari submasalah yang ada, maka solusi tersebut dikombinasikan ke dalam konsep pembuatan dan pengembangan produk connector wheelchair. Solusi yang dipilih adalah solusi yang dapat direalisasikan dan diterapkan pada produk connector wheelchair. Solusi tersebut diambil dari pohon klasifikasi submasalah yang diberi tanda $\sqrt{ }$, sedangkan solusi yang bertanda X tidak dipilih. Pada atribut material rangka, atribut keamanan da atribut mekanisme connector telah dipilih alternatif terbaik. Pada atribut material rangka dipilih material chromoly. Pada atribut keamanan dipilih sabuk pengaman dua titik, sedangkan untuk atribut mekanisme connector dipilih 
mekanisme mur dan baut. Sehingga, pada kombinasi tabel konsep alternatif untuk material rangka, atribut keamanan dan atribut mekanisme connector tidak dimasukan. Tabel 2 menunjukkan kombinasi dan penyusunan konsep produk connector wheelchair:

Tabel 2. Kombinasi konsep

\begin{tabular}{ccc}
\hline Kenyamanan & $\begin{array}{c}\text { Mekanisme Penggerak } \\
\text { Linear }\end{array}$ & $\begin{array}{c}\text { Mekanisme Melipat Roda } \\
\text { Depan }\end{array}$ \\
\hline Mono shock absorber & Hidrolis & Engsel gir \\
Double shock absorber & Pin pengunci & Magnet \\
\hline
\end{tabular}

Matriks concept screening untuk produk connector wheelchair diperlihatkan Tabel 3 berikut:

Tabel 3. Penyaringan konsep

\begin{tabular}{ccccccccc}
\hline Kriteria & $\mathbf{1}$ & $\mathbf{2}$ & $\mathbf{3}$ & $\mathbf{4}$ & $\mathbf{5}$ & $\mathbf{6}$ & $\mathbf{7}$ & $\mathbf{8}$ \\
\hline Kenyamanan & 0 & 0 & 0 & 0 & + & + & + & + \\
Mekanisme Penggerak Linear & - & - & 0 & 0 & - & - & 0 & 0 \\
Mekanimse melipat roda depan & - & 0 & - & 0 & - & 0 & - & 0 \\
Jumlah + & 0 & 0 & 0 & 0 & 1 & 1 & 1 & 1 \\
Jumlah 0 & 1 & 2 & 2 & 3 & 0 & 1 & 1 & 2 \\
Jumlah - & 2 & 1 & 1 & 0 & 2 & 1 & 1 & 0 \\
Total Nilai & -2 & -1 & -1 & 0 & -1 & 0 & 0 & 1 \\
Lanjutkan? & Ya & Ya & Ya & Ya & Ya & Ya & Ya & Ya \\
\hline
\end{tabular}

Tahap selanjutnya adalah melakukan concept rating (penilaian konsep) sesuai dengan kriteria kebutuhan pelanggan. Skala penilaian yang digunakan dalam concept rating adalah sebagai berikut:

$1=$ Sangat buruk dibanding konsep referensi

$2=$ Lebih buruk dibanding konsep referensi

3 = Sama dengan konsep referensi

4 = Lebih baik dibanding konsep referensi

5 = Sangat baik dibanding konsep referensi

Setelah dilakukan concept scooring, konsep yang dipilih untuk dikembangkan lebih lanjut adalah konsep 8, karena mempunyai nilai terbaik dibandingkan dengan konsep lainnya. Konsep 8 merupakan pengembangan produk connector wheelchair yang dibuat dengan menggunakan material chromoly. Material ini adalah material yang paling kuat dibandingkan dengan material alloy dan steel. Keamanan menggunakan sabuk pengaman dua titik. Double shock absorber/breaker digunakan pada konsep 8 untuk mendukung kenyamanan connector wheelchair, karena memiliki kemampuan menahan beban yang baik, serta umur lebih panjang.
Tabel 4. Concept scoring

\begin{tabular}{|c|c|c|c|c|c|c|c|}
\hline \multirow{2}{*}{ Kriteria } & \multirow{2}{*}{ Bobot } & \multicolumn{2}{|c|}{ Konsep 1} & \multicolumn{2}{|c|}{ Konsep2 } & \multicolumn{2}{|c|}{ Konsep 3} \\
\hline & & Rating & Nilai & Rating & Nilai & Rating & Nilai \\
\hline Kenyamanan & $35 \%$ & 3 & 1,05 & 3 & 1,05 & 3 & 1,05 \\
\hline $\begin{array}{l}\text { Mekanisme Penggerak } \\
\text { Linear }\end{array}$ & $30 \%$ & 2 & 0,60 & 2 & 0,60 & 3 & 0,90 \\
\hline $\begin{array}{l}\text { Mekanimse melipat roda } \\
\text { depan }\end{array}$ & $35 \%$ & 2 & 0,70 & 3 & 1,05 & 2 & 0,70 \\
\hline \multicolumn{2}{|l|}{$\begin{array}{c}\text { Total Nilai Ranking } \\
\text { Lanjutkan? }\end{array}$} & \multicolumn{2}{|c|}{$\begin{array}{c}2,35 \\
\text { Tidak } \\
\end{array}$} & \multicolumn{2}{|c|}{$\begin{array}{l}2,70 \\
\text { Tidak } \\
\end{array}$} & \multicolumn{2}{|c|}{$\begin{array}{l}2,65 \\
\text { Tidak } \\
\end{array}$} \\
\hline \multicolumn{8}{|c|}{ Tabel 4.25 Matriks Concept Scooring (Lanjutan) } \\
\hline \multirow{2}{*}{ Kriteria } & \multirow{2}{*}{ Bobot } & \multicolumn{2}{|c|}{ Konsep 4} & \multicolumn{2}{|c|}{ Konsep 5} & \multicolumn{2}{|c|}{ Konsep 6} \\
\hline & & Rating & Nilai & Rating & Nilai & Rating & Nilai \\
\hline Kenyamanan & $35 \%$ & 3 & 1,05 & 4 & 1,40 & 4 & 1,40 \\
\hline $\begin{array}{l}\text { Mekanisme Penggerak } \\
\text { Linear }\end{array}$ & $30 \%$ & 3 & 0,90 & 2 & 0,60 & 2 & 0,60 \\
\hline $\begin{array}{l}\text { Mekanimse melipat roda } \\
\text { depan }\end{array}$ & $35 \%$ & 3 & 1,05 & 2 & 0,70 & 3 & 1,05 \\
\hline \multicolumn{2}{|l|}{$\begin{array}{c}\text { Total Nilai Ranking } \\
\text { Lanjutkan? }\end{array}$} & \multicolumn{2}{|c|}{$\begin{array}{l}3,00 \\
\text { Tidak } \\
\end{array}$} & \multicolumn{2}{|c|}{$\begin{array}{l}2,70 \\
\text { Tidak } \\
\end{array}$} & \multicolumn{2}{|c|}{$\begin{array}{l}3,05 \\
\text { Tidak } \\
\end{array}$} \\
\hline \multicolumn{8}{|c|}{ Tabel 4.26 Matriks Concept Scooring (Lanjutan) } \\
\hline \multirow{2}{*}{ Kriteria } & \multirow{2}{*}{\multicolumn{2}{|c|}{ Bobot }} & \multicolumn{2}{|c|}{ Konsep 7} & \multicolumn{3}{|c|}{ Konsep 8} \\
\hline & & & Rating & Nilai & Ratin & & Nilai \\
\hline Kenyamanan & & $5 \%$ & 4 & 1,40 & 4 & & 1,40 \\
\hline Mekanisme Penggerak Linear & & $30 \%$ & 3 & 090 & 4 & & 1,20 \\
\hline Mekanimse melipat roda depan & & $35 \%$ & 2 & 0,70 & 4 & & 1,40 \\
\hline $\begin{array}{c}\text { Total Nilai Rankin } \\
\text { Lanjutkan? }\end{array}$ & & & & lak & & $\begin{array}{l}4,00 \\
\text { Ya }\end{array}$ & \\
\hline
\end{tabular}

Mekanisme connector menggunakan mur dan baut dipilih karena mudah untuk dilepas dan dipasang kembali, serta mur dan baut memiliki kekuatan yang cukup tinggi dalam menahan tegangan. Sedangkan, mekanisme penggerak linear dan mekanisme untuk melipat roda depan menggunakan pin pengunci dan magnet.

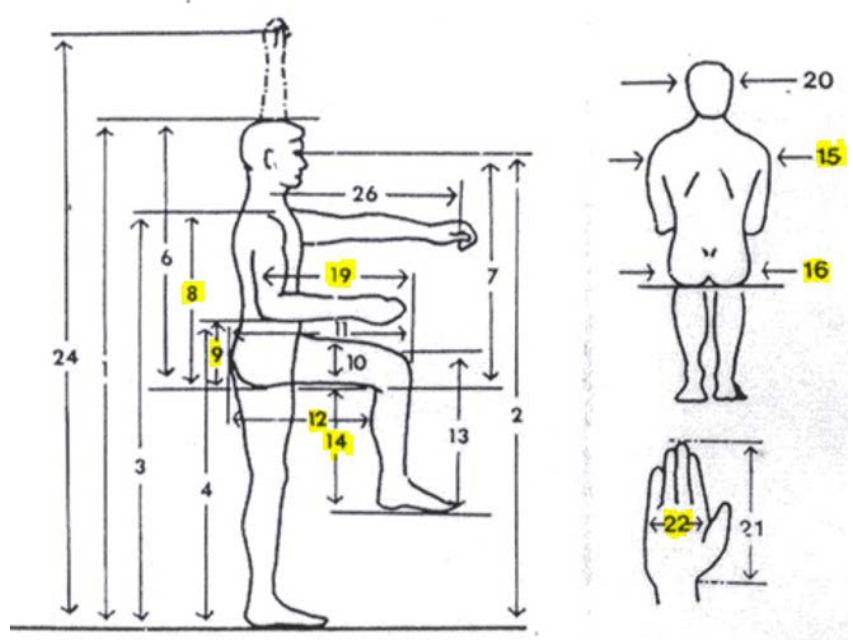

Gambar 2. Dimensi antropometri

Pada tahap desain produk terdapat perhitungan antropometri. Analisis antropometri digunakan untuk mendapatkan ukuran tubuh ideal. Terdapat 26 dimensi antropometri seperti yang dijelaskan pada Gambar 2 (Wignjosoebroto, 2008). 
Happy Ernesto Putra \& Sunday Noya Perancangan dan pengembangan connector wheelchair sebagai alat bantu tuna daksa

\section{Tabel 5. Ukuran tubuh}

\begin{tabular}{lc}
\hline \multicolumn{1}{c}{ Dimensi } & Ukuran $(\mathrm{cm})$ \\
\hline Tinggi bahu dalam posisi duduk diukur dari permukaan alas duduk & 63 \\
Tinggi siku, diukur dari permukaan alas duduk sampai bawah siku & 27 \\
Panjang paha yang diukur dari pantat sampai dengan bagian belakang & 53,5 \\
dari lutut atau betis & \\
Tinggi tubuh pada posisi duduk diukur dari lantai sampai bagian & 43,5 \\
bawah paha & 53 \\
Lebar bahu & 48 \\
Lebar pinggul atau pantat & 42 \\
Panjang siku yang diukur dari siku sampai ujung jari & 9 \\
Lebar telapak tangan & \\
\hline
\end{tabular}

Pada perancangan connector wheelchair akan digunakan 8 dimensi yaitu dimensi 8, dimensi 9, dimensi 12 , dimensi 14 , dimensi 15 , dimensi 16 , dimensi 19 dan dimensi 22

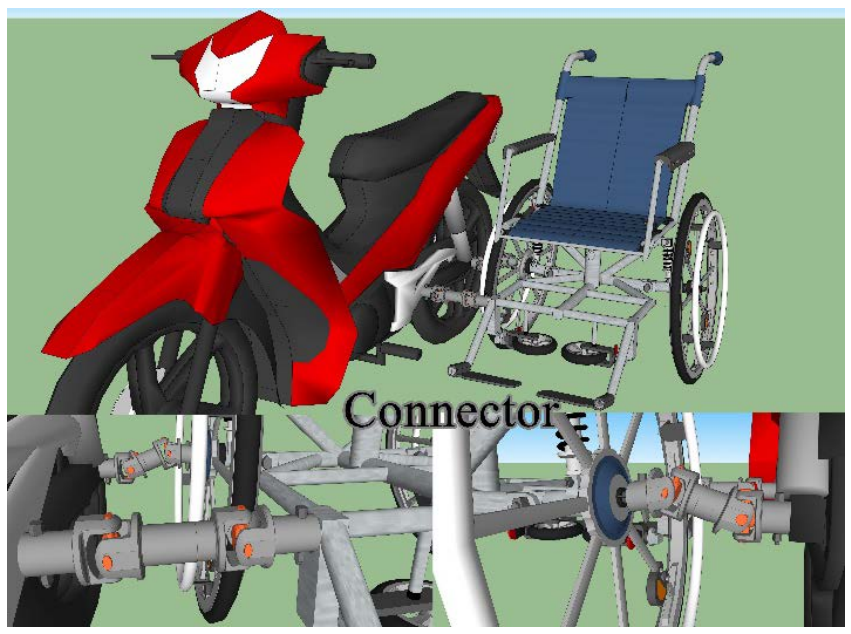

Gambar 3. Penggunaan connector wheelchair

\section{Kesimpulan}

Pada QFD tahap pertama, teridentifikasi atribut kebutuhan konsumen sebanyak 7 atribut. Atributatribut tesebut meliputi (1) material rangka kuat dan tahan lama, (2) kursi memiliki sabuk pengaman, (3) kursi roda memiliki shock absorber, (4) connector harus kuat, (5) kursi aman dan nyaman, (6) roda depan dapat dilipat, serta (7) ketinggian kursi dapat diatur. Berdasarkan atribut kebutuhan konsumen didapatkan enam sub-masalah. Sub-masalah tersebut antara lain mengenai material rangka, keamanan connector wheelchair, kenyamanan connector wheelchair, mekanisme yang digunakan pada connector, mekanisme penggerak linear untuk menaikan dan menurunkan tempat duduk pada connector wheelchair, serta mekanisme untuk melipat roda depan.

Konsep champion adalah konsep 8. Konsep 8 merupakan pengembangan produk connector wheelchair yang dibuat dengan menggunakan material chromoly. Material ini adalah material yang paling kuat dibandingkan dengan material alloy dan steel.

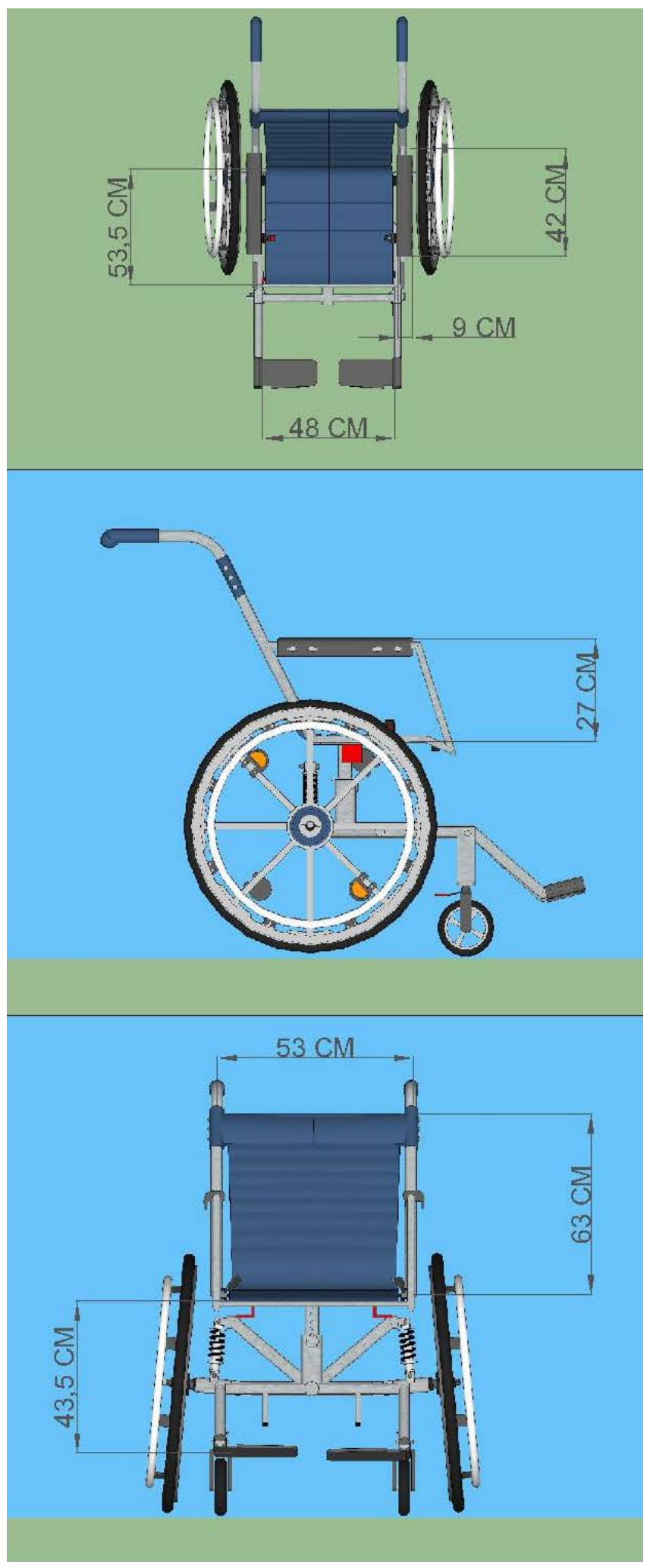

Gambar 4. Dimensi connector wheelchair 
Keamanan menggunakan sabuk pengaman dua titik. Double shock absorber/breaker digunakan pada konsep 8 untuk mendukung kenyamanan connector wheelchair, karena memiliki kemampuan menahan beban yang baik, serta umur lebih pajang. Mekanisme connector menggunakan mur dan baut. Mekanisme connector menggunakan mur dan baut dipilih karena mudah untuk dilepas dan dipasang kembali, serta mur dan baut memiliki kekuatan yang cukup tinggi dalam menahan tegangan. Sedangkan, mekanisme penggerak linear dan mekanisme untuk melipat roda depan menggunakan pin pengunci dan magnet.

\section{Daftar pustaka}

Anonim. (2012). Penduduk Indonesia menurut Provinsi 1971, 1980, 1990, 1995, 2000 dan 2010. Retrieved November 17, 2017, from https://www.bps.go.id/linkTabelStatis/view/id/1267

Ariani, D. W. (2002). Manajemen Kualitas: Pendekatan Sistem Kuantitatif. Yogyakarta: Proyek Peningkatan Penelitian Perguruan Tinggi Direktorat Jenderal Pendidikan Tinggi Departemen Pendidikan Nasional.

Ekawati, Y., Noya, S., \& Widjaja, F. (2017). Process quality planning of quality function deployment for carrot syrup. In AIP Conference Proceedings (Vol. 1855, p. 20009). AIP Publishing.

Kwong, C.-K., \& Bai, H. (2003). Determining the importance weights for the customer requirements in QFD using a fuzzy AHP with an extent analysis approach. Iie Transactions, 35(7), 619-626.

Noya, S., Ekawati, Y., \& Utami, N. (2017). Quality Function Deployment for Candied Carrots Process Planning. International Journal of Engineering and Advanced Technology Studies, 5, 1-7.

Pemerintah Republik Indonesia. (2016). Undang-Undang No. 8 Tahun 2016 tentang Penyandang Disabilitas. Lembaran Negara RI Tahun 2016, No. 69. Jakarta: Sekretariat Negara.

Rahadiansyah, R. (2017). Data Penjualan Motor Honda, Yamaha dkk. Retrieved November 17, 2017, from https://oto.detik.com/motor/3559408/data-penjualan-motorhonda-yamaha-dkk

Ulrich, K. T., \& Eppinger, S. D. (2012). Product Design and Development. New York: McGraw-Hill.

Wignjosoebroto, S. (2008). Ergonomi Studi Gerak dan Waktu, Surabaya, Guna Widya. W. Surabaya: Guna Widya.

Wijayanti, E., \& Noya, S. (2017). Integrating fuzzy-servqualinto importance performance analysis and quality function deployment for improve KSP Kusuma Artha Lestari service quality. Jurnal Ilmiah Teknik Industri, 1(3).

Zhang, F., Yang, M., \& Liu, W. (2014). Using integrated quality function deployment and theory of innovation problem solving approach for ergonomic product design. Computers \& Industrial Engineering, 76, 60-74. 